\title{
Trends in U.S. Trade Book Publisher Mergers and Acquisitions
}

\author{
David Lamb ${ }^{1}$
}

Published online: 18 June 2020

(c) Springer Science+Business Media, LLC, part of Springer Nature 2020

\begin{abstract}
Mergers and acquisitions (M\&A) activity involving book publishers is a continuing feature of the U.S. commercial publishing landscape. Over the last 6 years, from the beginning of 2014 through the end of 2019, there were 120 control transactions involving U.S. trade publishers of all sizes: on average, twenty transactions annually. This activity has proceeded subject to random annual variation uncorrelated to industry performance or to macroeconomic factors; in the last 2 years activity has accelerated, with 27 completed transactions in 2019. Historically, in the wake of the 2008 financial crisis, trade publishing M\&A activity stalled from the valuations achieved in 2006-2007, even as activity remained relatively steady. We anticipate that in the wake of the pandemic M\&A activity will gradually increase as publishers seek stronger partners and increased scale. In the first 5 months of 2020, eight transactions were announced or completed, and ViacomCBS set the stage for a major transaction by announcing its intention to divest Simon \& Schuster.
\end{abstract}

Keywords Mergers and acquisitions · Trade books · Finance $\cdot$ Valuation · Consolidation

\section{Terminology and Dataset}

The terms "merger" and "acquisition" refer to two legally distinct structures used to achieve a common goal: a business combination. While the term "merger" has a connotation of parity that "acquisition" may lack, there is no inherent implication that a merger is one of equals. Except when analyzing legal structure, the terms are largely interchangeable and will be treated so in this article. The omnibus term "mergers and acquisitions" or "M\&A" is somewhat redundant but in common use and will also be used here.

David Lamb

LambDCL@gmail.com

1 Partner, Book Advisors LLC, 232 Madison Avenue, Suite 1400, New York, NY 10016, USA 
Our firm, Book Advisors LLC, uses the term "trade publisher" to refer to publishers of books intended for consumption by consumers, as distinct from specialists or other practitioners (e.g., doctors, scientists, lawyers, accountants). The trade publisher universe, in our construct, includes university presses (rarely participants in M\&A activity) and religious publishers (more frequently involved in M\&A). It includes children's books but excludes books primarily used in educational settings. Audiobook publishers are included in transaction counts.

In analyzing M\&A trends in book publishing, we make use of a proprietary list of U.S. and U.K. trade book publishing transactions compiled by Book Advisors LLC. The transaction list includes financial metrics (purchase price, revenues, and profit) where these are available; this is not often the case, as most transactions are between private parties and financial metrics are undisclosed or subject to non-disclosure agreements.

The scale of the enumerated transactions varies in magnitude, from transactions involving small publishers or publishing lists completed for nominal consideration to the largest publishing transaction to date, the merger to form Penguin Random House and the subsequent, staged acquisition by Bertelsmann of Pearson's 47\% interest.

\section{Historical Context}

As in many industry sectors, mergers and acquisitions in book publishing have played a continual role in shaping the configuration of this industry. At times over the last 60 years, book publishers have been seen as attractive acquisitions for, variously, corporate conglomerates (1960s-1970s), diversified media companies (1980s), financial buyers (1990s-2000s), and, in the current market, primarily other book publishers. Some of these intervals reflected the corporate finance fashion of their time-the craze for conglomeration in the 1960s, the rise of private equity in the 1990s. Here, for example, is The New York Times reflecting, during the mergermad 1980s and as Harper \& Row became an acquisition target, on activity two decades prior:

“During the 1960's, publishing houses attracted a number of electronics giants, including RCA, which bought Random House; CBS, which bought Henry Holt, and I.T.T., which bought Howard Sams, the parent company of Bobbs-Merrill. They hoped to produce "teaching machines" from the marriage of their technical expertise and the publishers' editorial know-how, but their attempts ended in disappointment. In the case of Bobbs-Merrill, one of the few non-New York houses, its lists were pared, then its corporate owners prohibited it from publishing fiction, and finally it stopped publishing altogether."

\footnotetext{
1 Why Book Publishers Are Targets for Merger", The New York Times, March 17, 1987. https://www. nytimes.com/1987/03/17/books/why-book-publishers-are-targets-for-merger.html.
} 


\section{Number of U.S. Trade Book Acquisitions}

Number of transactions in period. Source: Book Advisors LLC. Compared to IMAA total U.S. deals.

U.S. Trade Book Deals Total IMAA U.S. Deals

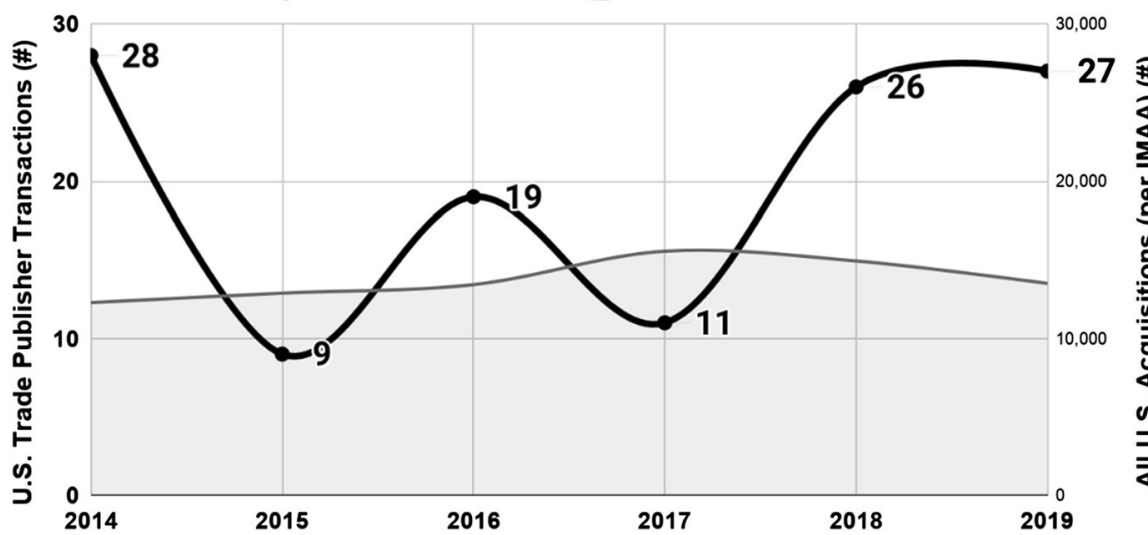

Fig. 1 Number of U.S. book publisher transactions, 2014-2019

Beyond corporate forays into trade book publishing, throughout the 20th Century and to the present day there has been a consistent stream of acquisitions of book publishers by their own kind, generally and logically involving the acquisition of smaller companies by larger companies (although with notable peer-to-peer exceptions such as the merger of Penguin Books and Random House in 2013).

At the height of economic activity prior to the onset of the Great Recession in 2008, trade book publisher M\&A was relatively steady. In line with the times, attendant valuations reached a high pitch, centered at a multiple of $100 \%$ of revenues (1X). Transactions involving Avalon Publishing (bought by Perseus Books Group) and Motorbooks International (Quarto) exemplified this relative peak.

In the wake of the Great Recession, transaction activity continued at a steady pace from 2009 through 2013, averaging one dozen transactions per year, even as the bankruptcy of chain retailer Borders Group and the introduction of ebooks complicated the landscape. Notable transactions from this period included the acquisitions of Ten Speed Press and Watson-Guptill by Random House; sequential sales of travel publisher Lonely Planet and religious publisher Thomas Nelson; the acquisition of Hyperion Books' adult list by Hachette from Disney; the sale of Zagat to Google; and the acquisition of Phaidon Press by Leon Black. As we shall see, transaction volume has picked up markedly in the last 6 years.

\section{Transaction Activity}

U.S. trade book publisher transaction volume varies year-to-year in a manner apparently uncorrelated with either industry performance or the larger economic environment. Figure 1 shows the annual number of U.S. trade book transactions, which ranges from peak activity of more than two dozen transactions in 2014 and again 


\section{U.S. Trade Book Dollar and Unit Sales}

Sources: AAP, NPD Bookscan, via Publishers Marketplace. Compiled by Book Advisors LLC.

AAP StatShot Trade-Only, Monthlies - \$ Million

NPD Bookscan - Total Units Million

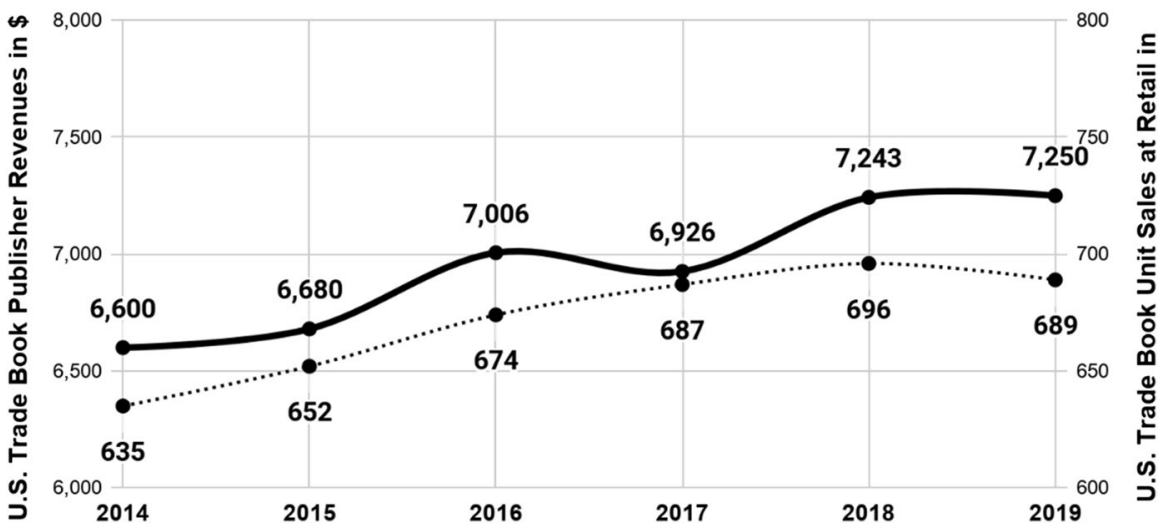

Fig. 2 Estimated sales of trade books in the U.S., 2014-2019

in 2018 and 2019, bookending lower volumes in 2015 to 2017. Transactions over the last 6 years total 120, an average of 20 per year. Activity has accelerated over the last 2 years, with a total of 53 transactions across the 24 months. This pace has been maintained through the first 5 months of 2020, with 8 announced or completed transactions.

For the sake of comparison, Fig. 1 also presents data collected by IMAA (Institute for Mergers, Acquisitions \& Alliances) documenting overall M\&A volume in the U.S. ${ }^{2}$ Per the IMAA tabulation, M\&A activity involved 13,506 transactions in 2019. Book transactions are a very small sample compared to overall M\&A activity-only .2\% of the IMAA total. The smooth IMAA curve, which swells to a subtle peak in 2017, stands in sharp contrast to the volatility in the number of trade publishing transactions.

As noted earlier, we can discern no clear correlates for the variability in book transactions. Overall industry sales over the 6-year period has been one of modest progression, as the publisher revenues and unit sales tabulated in Fig. 2 illustrate. Over this period the industry has enjoyed healthy print and leveling ebook sales, complemented by growing audiobook sales. The overall U.S. economic climate over the period was likewise one of continued robustness, with average $2.4 \%$ GDP growth over the period. ${ }^{3}$

\footnotetext{
${ }^{2}$ M\&A in the United States: Announced M\&A in the United States by Numbers and Value by Years. Institute for Mergers, Acquisitions and Alliances I https://imaa-institute.org/m-and-a-us-united-states/.

3 AAP November 2019 Stats Show Weak Sales". https://lunch.publishersmarketplace.com/2020/02/aapnovember-2019-stats-show-weak-sales/. Publishers Lunch, February 4, 2020. "AAP December 2019 Statshot Report" https://publishers.org/news/aap-december-2019-statshot-report-publishing-industry-up-1-8for-cy2019/. Association of American Publishers, March 10, 2020. "Now It's Official: Print Sales Were
} 


\begin{tabular}{|c|c|c|c|c|c|c|c|}
\hline ACQUIRER & 2014 & 2015 & 2016 & 2017 & 2018 & 2019 & $\begin{array}{c}\text { Grand } \\
\text { Total }\end{array}$ \\
\hline Rowman \& Littlefield & 2 & 3 & & & 2 & 3 & 10 \\
\hline PENGUIN RANDOM HOUSE & 1 & & & 1 & 1 & 2 & 5 \\
\hline HACHETTE & & 1 & 1 & 1 & 1 & & 4 \\
\hline Quarto & & & 4 & & & & 4 \\
\hline Chicago Review Press / IPG & 1 & & & 1 & & 2 & 4 \\
\hline Start Media & 3 & & & & 1 & & 4 \\
\hline Sourcebooks & & & & 1 & 1 & 1 & 3 \\
\hline Arcadia Publishing & 1 & & & & & 2 & 3 \\
\hline Turner Publishing Company & 1 & & 1 & & 1 & & 3 \\
\hline Fox Chapel Publishing & 1 & & & 1 & 1 & & 3 \\
\hline Open Road Integrated Media & 3 & & & & & & 3 \\
\hline HARPERCOLLINS & 1 & & & & 1 & & 2 \\
\hline Trustbridge Global Media & & & 1 & & 1 & & 2 \\
\hline Skyhorse Publishing & 1 & & & & & 1 & 2 \\
\hline Lerner Publishing Group & & 1 & & & 1 & & 2 \\
\hline Taylor \& Francis Group & & & 1 & 1 & & & 2 \\
\hline Kaplan & & & & & 2 & & 2 \\
\hline New Harbinger Publications & & 1 & 1 & & & & 2 \\
\hline Rosen Publishing Group & & 1 & 1 & & & & 2 \\
\hline Blackstone Audio Books & & & & 1 & 1 & & 2 \\
\hline Book Depot & & & & & 1 & 1 & 2 \\
\hline Deep Vellum & & & & & & 2 & 2 \\
\hline Iron Stream Media & & & & 1 & & 1 & 2 \\
\hline ALL OTHER & 13 & 2 & 9 & 3 & 11 & 12 & 50 \\
\hline TOTAL ALL TRANSACTIONS & 28 & 9 & 19 & 11 & 26 & 27 & 120 \\
\hline
\end{tabular}

Fig. 3 Most active U.S. trade book publisher acquirers. Number of U.S. trade book publisher acquisitions completed, by year

In the absence of defining industry or economic drivers, it is clear from the roster of most-active buyers that some of the variation in transaction volume stems from

Footnote 3 (continued)

Steady in 2019 (with An Asterisk)". Publishers Lunch, January 10, 2020. https://lunch.publishersmarke tplace.com/2020/01/now-its-official-print-sales-were-steady-in-2019-with-an-asterisk/. 
the small scale of many of the transactions. Figure 3 shows all acquirers that completed two or more acquisitions over the presentation period.

Among major publishers that have been active acquirers-notably Penguin Random House and Hachette-are mid-size publishers that have grown concertedly through acquisition. Leading this cohort is the Rowman \& Littlefield Publishing Group, which completed ten acquisitions including that of Globe Pequot Press. Other active mid-size acquirers have been Start Media, Chicago Review Press, Turner Publishing Company, and Sourcebooks. Some transactions included in the counts in Fig. 3 include small publishers acquiring yet smaller publishers or title lists, such as Deep Vellum's two acquisitions or those by Iron Stream Media (Table 1).

Naturally, the largest U.S. trade publishers-commonly referred to as the Big Five-have completed a number of acquisitions, at different intensities. Penguin Random House has been the most active acquirer, completing six U.S. transactions (excluding Bertelsmann's acquisition of Pearson's stake), followed by Hachette Books Group USA with four. HarperCollins' \$415 million acquisition of Harlequin Enterprises (then domiciled in Canada but with major U.S. and worldwide operations) was the largest transaction recorded among the Big Five in the period (Table 2).

\section{Transaction Value and Major Transactions}

Almost every trade publishing transaction consummated over the last 6 years involved a privately-held target. Additionally, relatively few acquirers report publicly, ${ }^{4}$ and even for those that do many of the acquisitions aren't of sufficient materiality for them to be reported. For very few transactions are data reported voluntarily. These features make it difficult to collect aggregate statistics regarding purchase price and aggregate dollar volume. Even more elusive are the financial results-revenues and profit - that allow for valuation parameters to be gauged. Finally, because aggregate dollar volume is driven by the largest transactions in a given year, median transaction size is not a terribly useful metric.

As a proxy for transaction volume, Table 3 presents a list of the largest U.S. book publisher transactions over the last decade. (This list includes some categories adjacent to trade publishing, although it excludes STM and textbook publishers and technology, service, distribution and retail companies). Transactions on this list involve either companies with revenues higher than $\$ 50$ million or transactions with values in excess of this level.

\footnotetext{
${ }^{4}$ Many are subsidiaries of larger publicly reporting companies, further increasing the materiality threshold, including four of the 'Big Five': Penguin Random House, Hachette, HarperCollins, and Simon \& Schuster. Other publicly-reporting companies include Bloomsbury, Quarto, and Scholastic.
} 


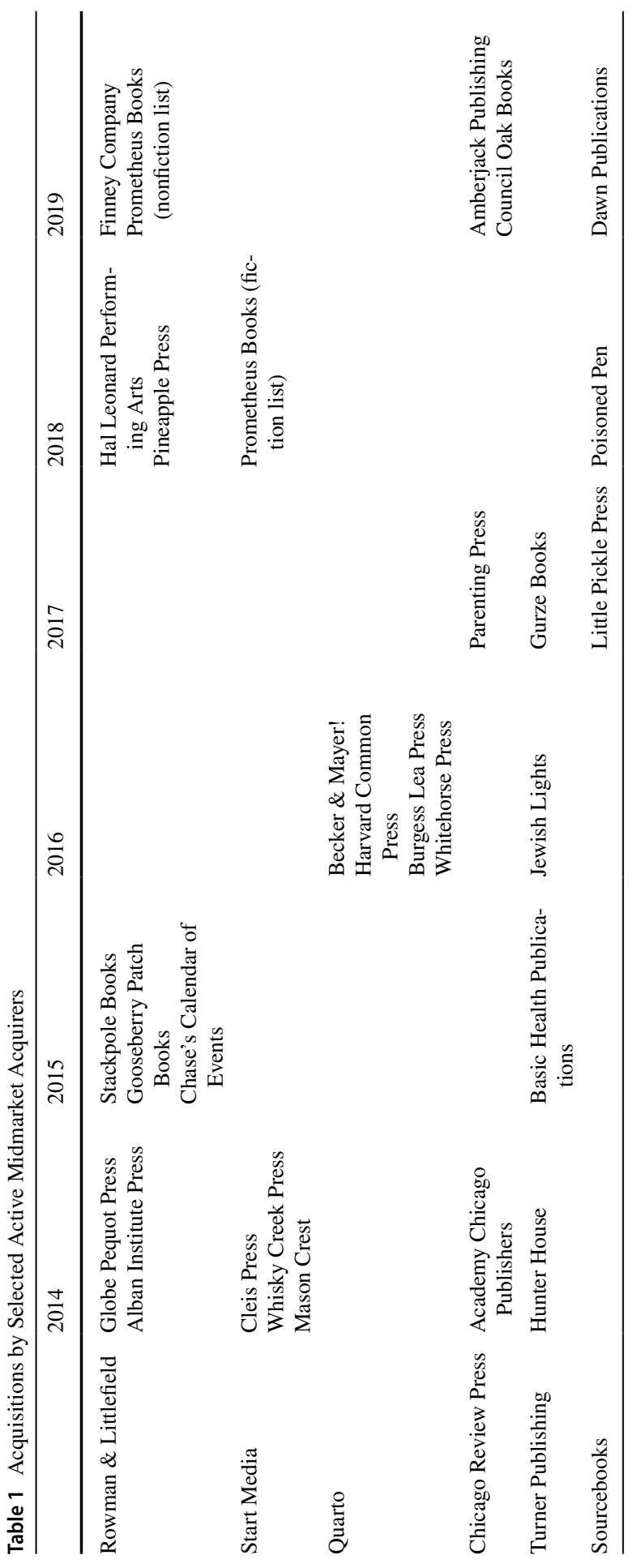




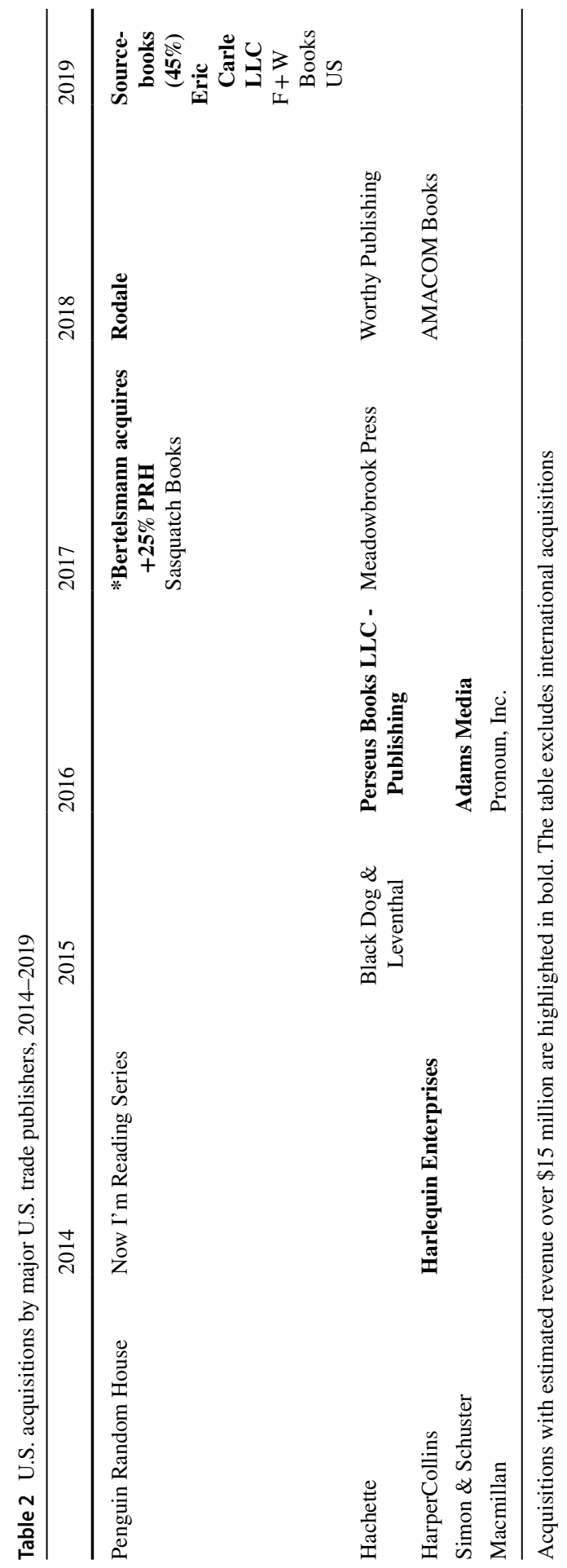




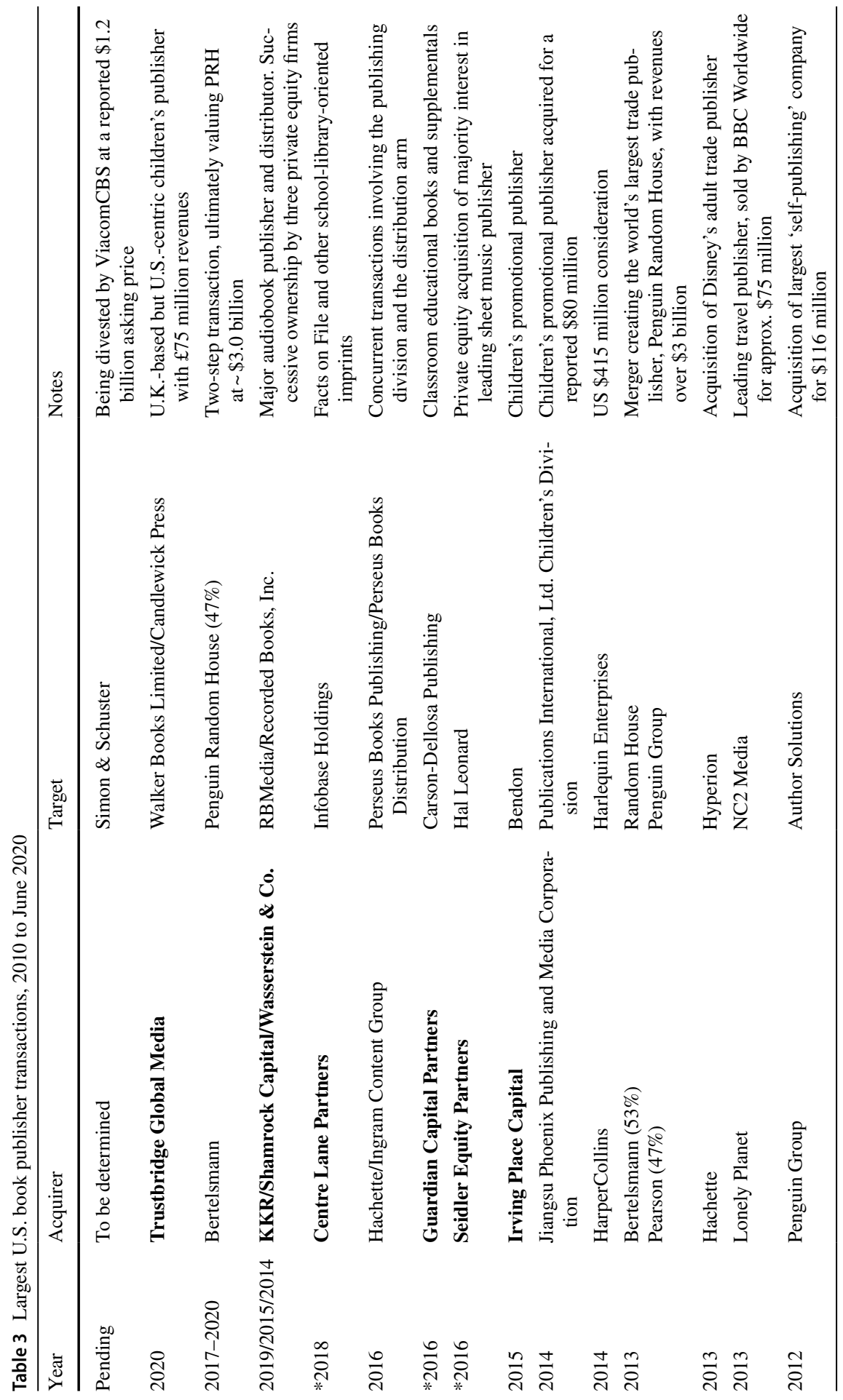




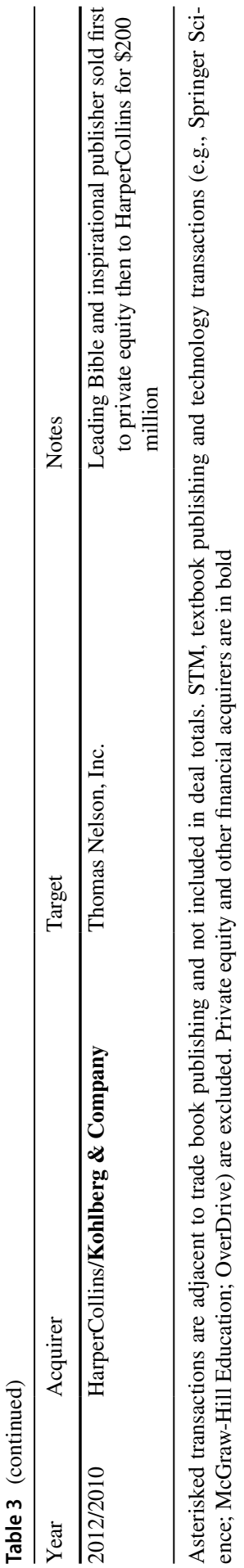

勿 Springer 


\section{Market Characteristics}

As can be seen from the IMAA statistics, trade book acquisitions account for just a fraction of a percent of overall M\&A activity. Further, trade publisher transactions have involved only a fraction of the thousands of American publishers, which admittedly range from those with several books and a few thousand dollars in sales ${ }^{5}$ to those with hundreds of employees and hundreds of millions of dollars in revenue. In our experience, trade book publishing constitutes a specific submarket for M\&A, with its own peculiarities, including the following:

- Selectivity. As in other creative industries, editorial considerations are critical in determining appropriate acquisition partners. The congruence and complementarity of a prospective partner's title list is usually central to acquisition decisions, and acquirers from the Big Five to the mid-market tend to demonstrate high selectivity in this regard. This selectivity means that often there are relatively few bidders with closeable interest in a given trade publisher-particularly at the smaller end of the range.

- Asset (List) acquisitions. The acquisition of a publishing list, without the attendant operating entity, has long been a popular mode of accumulating assets. It can be an efficient structure because the incremental titles are supported by the acquirer's existing infrastructure. It is also economically justified by the persistence of sales in a target's backlist. There is evidence that list acquisitions are increasing in popularity: in 2018 and 2019 nearly one-third of all transactions involved list purchases.

- Participation of financial buyers-at scale. Trade book publishing can consume considerable capital, particularly for a company seeking to grow: capital must be deployed well ahead of realized revenue, in royalty advances; illustration; editing, composition and printing; and shipping. (This is in addition to the fixed costs of maintaining publishing operations). Trade publishing is also, generally, a low margin business with $10 \%$ operating income margins considered healthy. These characteristics inhibit the use of leverage in acquisitions, which in turns lowers the returns financial buyers such as private equity funds can expect to achieve. These problems diminish at scale, and private equity buyers have been successful owners of significant publishers, as shown in Table 3.

The net effect of these factors is generally to inhibit market liquidity. With a lower degree of selectivity or with a more attractive financial profile, the trade publishing transaction market might burgeon-but without the hallmark of editorial point of view it would not be the industry that it is: an attractive one from a content and cultural perspective in which to participate.

\footnotetext{
5 The rapidly increasing output from self-published authors has further blurred the small end of the gradient. ISBN administrator Bowker estimates that 1.7 million titles were self-published in 2018, up 40\% from 2017. ("Number of Self-Published Titles Jumped 40\% in 2018," Publishers Weekly, October 15, 2019).
} 


\section{Outlook}

Even as the U.S. trade book industry continues consolidating, there are countless small and dozens of medium-sized publishers that are candidates for acquisition. These companies participate in an industry which increasingly rewards scale, both for its operational benefits (such as sales force efficiency) and because retail channels are increasingly consolidated. (Amazon and Readerlink all continue to gain share and this is likely to continue-and probably accelerate-post-pandemic.)

Although during the three peak months of the coronavirus lockdown in the U.S. sales of books were relatively resilient, the near- and mid-term effects of foregone sales and the uncertain bookstore environment may hobble some publishers and make it more incumbent for them to seek partners.

For the last 20 years, trade book publishing has been a minimal-growth industry, and whatever the transient effects of the pandemic, this is unlikely to change for the better over the next decade. A corollary of this forecast, particularly given pervasive risks going forward, is that waiting years for an exit may not be prudent even for those publishers that come through the crisis in a healthy way. Conversely, it is incumbent upon larger players to grow via acquisition if they wish to outperform. Accordingly, we anticipate that the recent high level of M\&A activity in U.S. trade book publishing will persist.

Publisher's Note Springer Nature remains neutral with regard to jurisdictional claims in published maps and institutional affiliations. 